\title{
Psycho-Social Determinants of Ethnocentrism: A Study among Four Ethnic Groups in Ghana
}

\author{
Victoria Wendy Lawson \\ Psychology Department, College of Humanities \\ University of Ghana, Ghana \\ vwlawson@ug.edu.gh \\ Maxwell Asumeng \\ Psychology Department, College of Humanities \\ University of Ghana, Ghana \\ Charity S. Akotia \\ Psychology Department, College of Humanities \\ University of Ghana, Ghana
}

\begin{abstract}
The study employed a descriptive correlational design in exploring psychological and social factors in a multi-ethnic community where ethnic prejudice is a probable root cause of conflict. Openness to experience and social dominance orientation were the psychological factors. The social factors were ethnic group membership and ethnic identification. A total of 240 respondents comprising Dagomba, Ga, Ewe and Akan ethnic groups were selected using quota and convenience sampling techniques. Questionnaire was used to collect data from the respondents. Findings from the standard multiple regression analysis of the data revealed that both psychological and social factors are significant determinants of ethnocentrism in a collectivist culture like Ghana. The result suggests that self-concept plays an essential role when discussing in-group favouritism.
\end{abstract}

Keywords: Ethnic groups, Ghana, Ethnocentrism, Self-concept.

\section{INTRODUCTION}

Africa has many ethnic groupings living together as a unitary state or a country. Naturally, such groupings generate bias attitude called prejudice [14]. Prejudice arises because of ingroup favouritism or ethnocentrism. Ironically most studies on this social psychological phenomenon have concentrated on racial groups in Western Europe and the United States with little done here in Africa. For instance, ethnocentrism has been investigated in relation to constructs such as openness to experience [8,9], social dominance orientation [23], group membership and group identification $[3,5,9,11,14,19,22]$. From these studies, it is evident that psychological and social variables explain ethnocentrism.

In Africa, most ethnic diverse countries like Kenya have many problems due to the 'tribe' mentality [20]. Also, the Rwanda Genocide which led to entire cleansing of ethnic group members and the Guinea fowl conflict in the northern part of Ghana attest the need to investigate into this ethnic incident. Very little is known about the dynamics of ethnocentrism in Ghana. There are scanty literature to explain the psycho-social factors of the ethnocentrism For instance, [21] mentioned that individuals should do their best in burying biases and prejudices. Afrifa [1] also discussed some conflicts which were due to ethnic classifications. It 
becomes necessary to explore ethnocentrism in a multi-ethnic nation like Ghana where bias attitude and in-group favouritism can cause conflict among various ethnic groups.

\section{Self-Concept theory}

\section{LITERATURE REVIEW}

The self-concept could be explained as a collection of beliefs about one's basic nature, unique qualities and typical behaviour with reference to the independent or interdependent self [18]. From the independent level, the self is personal and unique to others whilst the interdependency defines the self in connections with others. Generally, self-concept explains the behavior of individuals from two perspectives, the personal identity and social identity. All explanations for individual/personality differences fall under the personal identity whilst group-based investigations stem from the social identity.

Conceptuality, previous studies on ethnic based-bias usually examined the research variables using personality theories which explain individual differences or social psychological theories which capture the social identity of respondents. For instance, Pratto et al [23] used social dominance theory to examine people's orientation towards unequal status. Ekehammar et al. [8] study was on personality dispositions so the Big-five personality Inventory was used as the theoretical framework. Ekehammar et al [9] in their study explained ethnic prejudice from both social psychological and individual perspectives. In Ekehammar et al's [9] study, the two perspectives could have been explained in the framework of the self-concept. This is because the self-concept encompasses all the theories/perspectives that explained their findings of ethnic prejudice.

This study therefore employs the self-concept as a theoretical framework that explains the role of individual differences and group influence simultaneously. This means a discussion of ethnocentrism which springs from these two analyses will give a broader spectrum of the phenomenon.

\section{Related Studies}

The focus of previous studies on prejudice can be categorized under two main analysis, individual/personality differences and social psychological factors [17]. For instance, social identity theorists explaining prejudice from group based influence have made it clear that when one's identity become salient, individual differences which stem from personal identity should cease to predict prejudice. However, researchers $[8,13,24]$ who have explained prejudice from the individual differences approach have found a great deal of insight concerning the need to focus on these differences within groups. This implies that investigation of the two perspectives will help to understand the dynamics of ethnic prejudice. The argument therefore, should not be centred on which one should be used to explain ethnic prejudice, rather how the two can best be utilized to explain the phenomenon. However, there is a similar study by Ekehammar et al. [9] which combined the two perspectives but in the Western culture using racial device as a measure of ethnicity.

The study seeks to explore the role of personality factors such as openness to experience and social dominance orientation and the role of social-psychological factors such as ethnic membership and identification in explaining ethnocentrism.

\section{Personality differences and Ethnocentrism}

Empirical studies have established that personality which is unique pattern of enduring psychological and behavioural characteristics by which a person can be compared and contrasted with other people has a role to play in examining prejudice [9]. The focus of 
researchers pertaining to personality approach of explaining ethnocentrism is on examining individual differences among a group and how these differences could lead to in-group bias. The Big-Five Personality Trait Inventory has helped in some reasonably way to understand and appreciate the role of personality in explaining prejudice [24]. In a Meta-Analysis, Sibley and Duckitt [24] revealed that personality in general terms guides behavior and the consequence of it on prejudice toward a group which in contrast may be attenuated by specific beliefs being held about that particular social category.

Pratto et al proposed another individual-difference dimension, social dominance orientation (SDO) aside personality traits which is "general attitudinal orientation toward intergroup relations, reflecting whether one generally prefers such relations to be equal, versus hierarchical" and the "extent to which one desires that one's in-group dominate and be superior to out-groups" [23 p. 742]. Pratto et al [23] study revealed that SDO predicts ingroup favouritism. Esses [10] in his study, disclosed that individuals who prefer social inequality hold belief that perpetuate ethnocentrism. Also it was revealed in Pratto et al [23] study that individuals who score high on SDO are more likely to be prejudicial. This means SDO is not a trait but helps to understand differences among individuals when the focus is on values and not group-based factors.

\section{Social Psychological factors and Ethnocentrism}

The 1960s brought a change concerning the focus of researchers in the field of prejudice and intergroup attitude. There was a change from the personality analysis to social and intergroup influence as a result of theoretical and methodological flaws by the then researchers like Adorno and Pettigrew [24]. This new way of evaluating prejudice led to the various theories stemming from group based explanations because it became necessary to incorporate this perspective in the quest of understanding in-group favouritism and out-group hostility. This is so because prejudice is more of a group phenomenon [17]. From this perspective then, it is important when discussion ethnocentrism to include group identity where an individual categorizes the self as a member of a particular group and not another and how both the group membership and group identification could influence members to behave in discriminatory way towards out-groups. The group-based approach explains ethnocentrism from the group that an individual belongs, and according to researchers who support this theory, much attention should be placed on the nature of group dynamics when dealing with ethnocentrism. Findings from these studies help to understand a person's behaviour from his/her group affiliation. For instance in a study by Castano and Yzerbyt [2], research participants were provided with some traits and these respondents were to select from the given attributes the ones that qualify their groups.

As the researchers expected, all the participants used positive traits to describe the group they belong, showing in group bias. It was also revealed that just being a member of a class of student was enough to discuss your group but how well a student identifies with the class counts a lot in that high identifiers used saw the in-group to be homogenous on positive attributes than the out-group. This means when people are to judge whether there are differences among the group they belong and that of the out-group; the probability to see favourable traits among the in-group is high. This behaviour is explained by social identity theorists as a form of enhancing the self where emphasis is placed on how the self depend on other selves in the group. when people are categorize into groups, the group gives the individual a sense of identity, so anytime they are to compare the group to other groups which they don't affiliate that basic tendency to rate the in-group favourably over the group they don't belong is high. 
Based on the review of related studies, the following hypotheses were formulated and tested:

$\mathbf{H}_{1}$ : There would be a significant positive relationship between ethnic identification and ethnocentrism

$\mathbf{H}_{2}$ : There would be a significant positive relationship between Social Dominance Orientation and ethnocentrism

$\mathbf{H}_{3}$ : There would be a significant negative relation between Openness to Experience and ethnocentrism

\section{Participants}

\section{METHODS}

The four major ethnic groupings in Ghana according to the 2010 population and housing census report entailed the population for the study. The major ethnic groups are Akan Ga, Dagomba and Ewe. The researchers used quota and convenience sampling techniques to select 240 participants and the sample size is based on Cohen's [4]statistical power. From Cohen's Statistical Tables, the sample sizes necessary for .80 powers at the .05 level of significance for Pearson $r$ is 85 and regression a total of 118 respondents needed.

\section{Design}

The correlational/multi-linear regression and cross-sectional survey design were the appropriate designs for the study because the study sought to explore the variables that could predict ethnocentrism. The correlational/multi-linear regression design strategy permits researchers to study and describe the nature of the relationships between variables using simple correlation or regression [12]. The cross-sectional survey was employed in addition to the correlational survey design because as at the time of the data collection, not all members of the chosen ethnic groups were included but a cross-section of the data in terms of age, gender and education. Likewise the data was collected from the population at only one point in time.

\section{Measures/ Materials}

Big-Five Inventory- The Big-Five factors are Openness to Experience, Conscientiousness, Extraversion, Agreeableness and Neuroticism. The inventory by John and Srivasta [15] is made up of 44 five-point Likert-scale items ranging from disagree strongly to agree strongly. Some of the items are, I see myself as "talkative; tend to find fault with others; does a thorough job; is depressed, blue; is original, comes up with new ideas". A meta-analytical study by Sibley and Duckitt [24]reviewed that Openness to Experience correlates more with SDO and prejudice, so this factor was adopted for the study. The alpha reliability coefficient of Openness to Experience is 0.86 .

Social Dominance Orientation- Pratto et al's [23] social dominance orientation scale which is used to assess individual's preference for inequality among social-groups was used for the present study. This measurement consists of 15 seven-point Likert-scale items ranging from very negative to very positive. The SDO scale has the first 8 items favoring approval of social equality whist the remaining 7 items favor inequality. These 15 statements include "Some groups of people are simply inferior to other groups," "All groups should be given an equal chance in life," and "Inferior groups should stay in their place." The alpha reliability coefficient of the scale is 0.90. It is difficult translating the various responses of the Likert scale in the Ghanaian dialects chosen, so the scale was reduced to four-point. The Pilot study showed a higher reliability of 0.87 which means the modified scale served the purpose as the original. 
Ethnic Identification- This measure was used to find out how individuals within an ethnic group felt close or attach to their group. Meeus et al's [19] constructed this scale with four items. The alpha reliability coefficient of the scale is 0.83 . This scale is scored on 4-point Likert scale which ranges from 1 (strongly disagree) to 4 (strongly agree) where high scores denote one's closeness with in-group. An item is "I feel a bond with my in-group members".

Ethnocentrism- Meeus et al's [19] 6 four-point Likert scale item which has alpha reliability coefficient of 0.92 was employed for this study. Among the items include; 'The presence of Moroccans are a threat to Belgium'. The researchers adopted and revised the scale to suit the current study, where Moroccans were replaced with out-groups since the present study examined multiple out-groups (Dagomba, Ga, Ewe and Akan) and Belgium was substituted with in-group ethnicity.

\section{Procedure}

Research assistants were employed to distribute the questionnaire for the study. During the data collection, respondents kept asking for the meaning of some of the items since those items were not clear to them, the respondents. This led the researchers to further explain the items 6, 7, 8 and 10 of the openness to experience measure. For instance item 10 contains "sophisticated" which was simplified to "finer, better". So the researchers altered these items to tailor the present study. These changes became necessary for the questionnaire to be piloted. Thus data was collected from a section of the population which was analysed for two main reasons; to check for the reliability of the modified measures, and whether respondents understood the items on the questionnaire. A sample size of 40 was selected for the pilot study but thirty-two out of the forty distributed questionnaire were fully filled so the remaining eight half-filled were excluded from the analysis. The reliability coefficient for the various sub-scales are as follow; $\mathrm{SDO}=0.87$; Ethnic Identity $=0.83$; Ethnocentrism $=0.72$; and Openness to experience $=0.70$. It took about three months for the researchers to collect data for the main study from the respondents of the chosen ethnic groups. The verbal consent of the respondents was sought before they were allowed to partake in the study. After completion of the questionnaire, respondents were thanked. The cronbach alpha of the research variables for the main study were as follows; $\mathrm{SDO}=.857$, Openness to Experience $=$ .702 , Ethnic Identification $=.834$, Ethnocentrism $=.798$.

\section{RESULT}

In all, the analyses of data were under two phases; descriptive and hypothesis testing; and standard multiple regression analysis.

\section{Descriptive statistics and Hypotheses}

Table 1: Descriptive Statistics and Inter-correlation Matrix of the Study Variables ( $=240)$

\begin{tabular}{lllllll}
\hline & $\mathrm{M}$ & $\mathrm{SD}$ & 1 & 2 & 3 & 4 \\
\hline 1SDO & 29.02 & 8.23 & & & & \\
2Ethnic identification & 14.03 & 2.26 & $-.127^{*}$ & & & \\
3Ethnocentrism & 14.11 & 5.06 & $.180^{* *}$ & $.359^{* *}$ & & \\
40penness to Experience & 30.34 & 4.35 & $-.266^{* *}$ & $.124^{*}$ & $-.110^{*}$
\end{tabular}

\footnotetext{
${ }^{*} p \leq .05 \quad \mathrm{SDO}=$ Social Dominance Orientation

${ }^{* *} p \leq .01$
} 


\section{Hypothesis One}

$\mathbf{H}_{1}$ : There would be a significant positive relationship between ethnic identification and ethnocentrism.

The results from table 2 indicated that there was a significant positive relationship between ethnic identification and ethnocentrism $(r=.359, p<.01)$. The coefficient of .359 shows there is a medium effect according to Cohen's descriptors. Thus, the more one identifies with his/her ethnic group the more he/she favours the in-group members. From this, the hypothesis that 'there would be a significant positive relationship between ethnic identification and ethnocentrism' is supported.

\section{Hypothesis Two}

$\mathbf{H}_{2}$ : There would be a significant positive relationship between Social Dominance Orientation and ethnocentrism.

Result indicated that there was a positive significant effect of SDO on ethnocentrism $(r=.180$, $p<.01$ ). This means that there is a small effect size of SDO on ethnocentrism, where one prefers unequal status in society the more ethnocentric the person becomes. The research hypothesis that "there would be a significant positive relationship between Social Dominance Orientation and ethnocentrism" is therefore confirmed.

\section{Hypothesis Three}

$\mathbf{H}_{3}$ : There would be a significant negative relationship between Openness to Experience and ethnocentrism.

The summary results of hypothesis three from table 1 showed that there was a negative significant relationship between Openness to Experience and ethnocentrism $(r=-.110, p<$ $.05)$ and the effect size is small. The result means that there is an inverse relationship between Openness to Experience and ethnocentrism, where a higher score on Openness to Experience personality inventory leads to a lower score on ethnocentrism. Thus, an individual is prone to be ethnocentric when he/she is low on Openness to Experience. From this, the hypothesis that "there would be a significant negative relationship between Openness to Experience and ethnocentrism" is supported.

\section{Standard multiple regression}

Hypotheses 1, 2 and 3 were supported. This suggests that ethnic identification, social dominance orientation and openness to experience had significant relationship with ethnocentrism. The standard multiple regression was further used to determine the variance each role contributes to the criterion. Thus, in determining predictive factors of ethnocentrism among Akans, Gas, Ewes and Dagombas in Ghana, the standard multiple regression was run. The results are presented on Table 2.

Table 2: Results of Standard Multiple Regression Analysis for Personality variables and Social psychological variables as Predictors of Ethnocentrism

\begin{tabular}{lccc}
\hline & B & SEB & $\beta$ \\
\hline Social Dominance Orientation & .118 & .037 & $.192^{*}$ \\
Ethnic identification & .823 & .134 & $.367^{*}$ \\
Openness to experience & -.104 & -.104 & $-.090^{*}$ \\
\hline
\end{tabular}

${ }^{*} p \leq .05$ Note $\mathrm{R}^{2}=.213, \Delta \mathrm{R}^{2}=.213$ 
The summary table indicated a significant model, $R^{2}=.213, F_{(4,235)}=15.876, p<.01$, Adjusted $R^{2}=.213$. That is $21.3 \%$ of the variance in ethnocentrism can be explained by ethnic identification, SDO and openness to experience. The variables in order of the most influential are ethnic identification $(\beta=.367)$, SDO $(\beta=.192)$ and openness to experience $(\beta=-.090)$.

\section{Summary of Predictors of ethnocentrism}

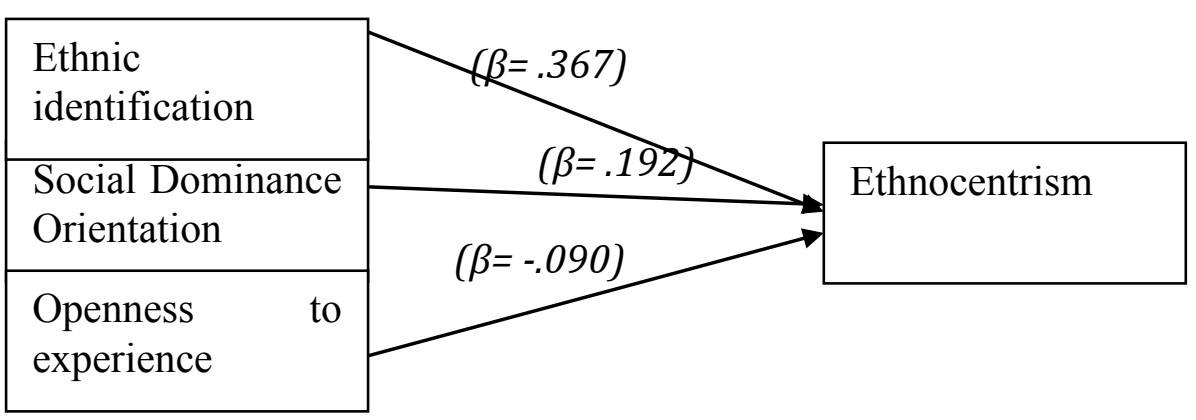

Figure1: The diagrammatic model depicts the predictive relationship among variables as observed in the present study

\section{DISCUSSION \\ Relationship between Ethnic identification and Ethnocentrism}

It was hypothesized in the present study that there would be a significant positive relationship between ethnic identification and ethnocentrism, where ethnic identification is having a bond with one's ethnic group and not just being a member. This hypothesis was supported, meaning the more one identifies with his/her ethnic group the more likely he/she is to favour his/her group over other ethnic groups. Thus an Akan member who feels a close bond with his/her Akan identity sees other ethnic groups such as Dagomba or Ewe as a threat to his/her in-group and therefore will do everything possible to maintain the in-group vrs. out-group classification. This finding is consistent with some past empirical evidence $[5,9,10$, $16,19,22]$. The present study has revealed that in-group bias could be explained from the attachment individuals feel for their group. This is evident from the self-concept that the desire and the search for positive self-esteem could be derived from the group an individual belongs to. So the need for the positive self-esteem caused the members of each ethnic group to show ethnocentric tendency which can lead to discriminating against out-groups.

\section{Relationship between SDO and Ethnocentrism}

Hypothesis two stated that there would be a significant positive relationship between Social Dominance Orientation and ethnocentrism. The findings of the study reported a significant positive relationship between SDO and ethnocentrism. In this study, SDO was used as a surface personality variable because it measures the values of individual in society with attention on social inequality. All personality studies $[9,10,13,17,23,24-26]$ that included this measure found a significant relation with ethnic prejudice. This means individual preferences for inequality, holding onto group status predispose the person to be bias towards individuals who do not belong to that particular status. Here, the focus is not on the group identity but the values of individuals. This means that an individual will be bias toward an in-group ethnic member if such in-group member does not share or hold same values and beliefs as the individual. From the personal identity of the self-concept, a person who belongs to an ethnic group and identifies with it still possess some values that differentiate him/her from other members of the same social identity. 


\section{Relationship between Openness to Experience and Ethnocentrism}

The finding of the study reported that there was a significant negative relationship between Openness to Experience and ethnocentrism. The significant negative relation explains that a higher score on Openness to experience leads to a lower score on ethnocentrism. In other words, the more open one is to ideas the lesser in-group favouritism the person exhibits. Openness to experience is one factor of the Big-five Personality Inventory which has been found to have a relationship with ethnic prejudice $[7,8,24-26]$. The result of the present study is in line with these previous studies.

Ekehammar et al, [9] have reported that personality and social psychological factors explained ethnic prejudice better than only one factor. The researchers included the Big-five personality Factors in their study. Specifically Openness to experience was used in relation with Right-wing Authoritarianism and SDO. It was revealed that low Openness to experience individuals where more prejudiced. Openness to experience as a trait explains that individuals who possess it are creative, and play with ideas. Such individuals are more likely to associate with others irrespective of their group identity. Innate quality tends to form the reason why people show prejudicial attitude towards others and not the group they affiliate having influence on their bias attitude. So individuals who do not associate with out-groups tend to feel a stronger bond with their in-group identity. The intensity of the bond with the group causes them to defend and rate others using the in-group as a reference point. It therefore means that individual differences in terms of trait explanation should be included in ethnocentrism studies.

\section{Theoretical and Social implication}

Theoretically, this study has established some of the determinants of ethnocentrism in a multi-ethnic society. It confirms empirical support of the studies done by Leeson [17] and Ekehammar et al [9] which assert that ethnocentrism or prejudice should be analysed from both individual and group-based explanations because each has a significant relationship with ethnocentrism. This is evident in the standard multiple regression analysis where significant relationships existed between personality variables, ethnic identification and ethnocentrism. This study further incorporates the two explanations into one theoretical concept, the selfconcept which helps to understand and appreciate the dynamic nature of the self in explaining ethnocentrism.

Following the dual model approach proposed by Ekehammar et al., this study further incorporates the two explanations into one theoretical concept, the self-concept. The selfconcept involves personal and social identity. All explanations for individual differences fall under the personal identity whilst group-based investigations stem from the social identity and a discussion of ethnocentrism which springs from these two angles give a broader spectrum of the phenomenon.

Socially, the study provides government institutions, nongovernmental organizations, research practitioners and policy makers with insight into the nature and dynamics of intergroup attitudes in Ghana. This offers an in depth knowledge into how consciousness raising could serve as a platform in social change. Emphasis should be laid on how consequences of in-group favouritism could affect the development of a nation. The present study also helps to modify the educational curriculum where topics such as diversity could be treated in depth. Matters in relation to individual values, beliefs and traits should not be over looked when resolving inter-group conflicts because they correlate significantly with ethnocentrism. 


\section{Limitations and Suggestion for future research}

The study explored relationships among variables which mean establishing causal relationship is not possible. There are many factors that may account for ethnocentrism, as in the present study, only $21.3 \%$ of the variance was accounted for. Hence, future researchers should explore these possible predictive factors.

\section{CONCLUSIONS}

The study aimed at exploring the possible determinants of ethnocentrism among four ethnic groups in Ghana in an inter-group situation. The study has revealed that SDO, Openness to experience and ethnic identification are the predictors of ethnocentrism. From the standard regression analysis, a framework that focuses on both personality and social psychological models would help understand ethnocentrism better. Despite its limitations, the results of the present study are interesting and compelling.

In summary, ethnocentrism therefore could be seen as a strategy for achieving and maintaining self-esteem. The tendency to be bias towards in-group members and against outgroup members is by paying more attention to criteria that make one's in-group look better than salient out-groups. So the desire to maintain a positive self-concept creates pressure to evaluate one's own group positively. Aside the groups that individuals identify with their innate traits, values and beliefs in life also cause them to be prejudicial towards others. The emphasis is on personality differences where group affiliation has no role in influencing the bias attitude of in-group members. So in-group members could be prejudicial towards their own group members because they do not share the same traits and values that guide their behaviour.

\section{References}

[1]. Afrifa, A., The Menace of Ethnic conflicts. Uhuru, 1994. 6: p. 16-17

[2]. Castano, E. and V. Y. Yzerbyt, The highs and lows of group homogeneity. Behavioural Process, 1998. 42: p. 219-238

[3]. Castillo, L. G., et al., Predictors of Racial Prejudice in White American Counseling Students. Journal of Multicultural Counseling \& Development, 2006. 34(1): p. 15-26. Retrieved from EBSCOhost.

[4]. Cohen, J., Quantitative Methods in Psychology: A Power Primer. Psychological Bulletin, 1992. 112 (1): p. 155159

[5]. Condor, S., Public Prejudice as Collaborative Accomplishment: Towards a Dialogic Social Psychology of Racism. Journal of Community \& Applied Social Psychology, 2006. 16: p. 1-18

[6]. Dudley, M. G., and D. Mulvey, Differentiating among out-groups: predictors of congruent and discordant prejudice. North American Journal of Psychology, 2009. 11(1): p. 143-156

[7]. Duriez, B., and B. Soenens, Personality, Identity Styles and Authoritarianism: an Integrative study among Late Adolescents. European Journal of Personality, 2006. 20 (5): p. 397-412

[8]. Ekehammar, B., N. Akrami, The Relation between Personality and Prejudice: A variable-and a personcentred approach. The European Journal of Personality, 2003. 17: p. 449-464

[9]. Ekehammar, B., N, Akrami, and F. Yang-Wallentin, Ethnic prejudice: A combined Personality and Social Psychology Model. Individual Differences in Research, 2009.7 (4): p. 255-264

[10]. Esses, V. M., The Role of Lay Perceptions of Ethnic Prejudice in the Maintenance and Perpetuation of Ethnic Bias. Journal of Social Issues, 2006. 62 (3): p. 453-468

[11]. Frey, L. L., and G. Roysircar, South Asian and East Asian International Students' Perceived Prejudice, Acculturation and Frequency of Help Resource Utilization. Journal of Multicultural counseling and development, 2006. 34: p. 208-222 
[12]. Gravatter, F. J., and L. A. Forzano, Research Methods for the Behavioural Sciences. 2nd edition ed2006, Thomson Wadsworth:(U. S.A)

[13]. Guimond, S., et al., Does Social Dominance Generate Prejudice? Integrating Individual and contextual Determinants of Intergroup Cognitions. Journal of Personality and Social Psychology, 2003. 84 (4): p. 697-721

[14]. Hornsey, M. J., Social identity theory and self-categorization theory: A historical review. Social and Personality Psychology Compass, 2008. 2: p. 204-222

[15]. John, O. P., and S. Srivasta, The Big Five trait taxonomy: History, measurement and theoretical perspectives. Chapter 4, 1999. University of California, Berkeley.

[16]. King, K. R. Do you see what I see? Effects of Group Consciousness on African Women's Attributions to prejudice. Psychology of Women Quarterly, 2003. 27: p. 17-30

[17]. Leeson, P. R. C., The role of social identities and individual differences on predicting prejudice: a plea for tolerance. 2006. http://ro.uow.edu.au/theses/134

[18]. Markus, H. R., and S. Kitayama, Culture and the Self: Implications for Cognition, Emotion and Motivation. Psychological review, 1991.98 (2): p. 224-253

[19]. Meeus, J., et al., The role of national identity representation in the relation between in-group identity and out-group derogation: Ethnic versus civic representation. British Journal of Social Psychology, 2010. 49:p. 305-320

[20]. Nakamura, K. Students'Perceptions of Ethnicity and Learning: A case study of the United States International University. Journal of Language, Technology \& Entrepreneurship in Africa, 2009. 1 (2): p. 76-89

[21]. Nyarko, K. Bestiality of tribal bigotry. 2010, February 03. The Ghana web. Retrieved from http://www.ghanaweb.com/ghanahomepage/features/artikel.php? ID=176103

[22]. Pettigrew, T. F., et al., Relative Deprivation and Intergroup Prejudice. Journal of Social Issues, 2008. 64 (2): p. 385-401

[23]. Pratto, F., Sidanuis, J., Stallworth, L. M., and Malle, B. F. Social Dominance Orientation: A personality variable predicting social and political attitudes. Journal of personality and Social psychology, 1994. 67 (4): p. 741-763

[24]. Sibley, C. G., and J. Duckitt, Personality and Prejudice: A Meta-Analysis and Theoretical Review. Personality and Social Psychology Review, 2008. 12 (3): p. 248-279

[25]. Sibley, C. G., and J. Duckitt, Big-Five Personality, Social Worldviews, and Ideological Attitudes: Further Tests of a Dual Process Cognitive-Motivational Model. Journal of Social Psychology, 2009. 149 (5) : p. 545-561

[26]. Sibley, C. G., and J. Duckitt, The Personality Bases of Ideology: A One-Year Longitudinal Study. The Journal of Social Psychology, 2010. 150 (5): p. 540-559 